\title{
Comparison of Point and Snow Load Deflections in Design and Analysis of Tensile Membrane Structures
}

\author{
Vuk S. Miloševićc (iD and Biserka Lj. Marković \\ Faculty of Civil Engineering and Architecture, University of Niš, Niš 18000, Serbia \\ Correspondence should be addressed to Vuk S. Milošević; vukamer@yahoo.com
}

Received 22 July 2020; Accepted 25 November 2020; Published 9 December 2020

Academic Editor: Chiara Bedon

Copyright @ 2020 Vuk S. Milošević and Biserka Lj. Marković. This is an open access article distributed under the Creative Commons Attribution License, which permits unrestricted use, distribution, and reproduction in any medium, provided the original work is properly cited.

\begin{abstract}
Tensile membrane structures are often used as protective structures in order to provide cover from snow, rain, and direct sunlight. They are widely popular because of their advanced structural and architectural properties. Currently, their application is common at sport stadia and public spaces. There are several types of loads acting on tensile membrane structures, most importantly prestress, snow load, and wind load. However, concentrated loads also act on these structures, but they are frequently neglected during the structural analysis. There is yet no European standard on designing tensile membrane structures that would give guidance on structural analysis and incorporation of point load actions in the analysis. In addition, there is little scientific knowledge on how point loads affect tensile membrane structures. This research aims at revealing whether point loads can produce significant membrane deflections and in such way cause damage to the structure or to the objects underneath the membrane. In order to evaluate their importance, point load deflections are compared to deflections induced by snow load. This was done on a large number of numerical models differing in several parameters. Models represent typical geometries of hypar membrane structures on a square base. Obtained results show that, in many cases, point loads can produce larger membrane deflections compared to the snow load. This finding will have an impact on including the point load actions into standardization of design and analysis procedures of tensile membrane structures in Europe.
\end{abstract}

\section{Introduction}

Tensile membrane structures are sophisticated successors of tents, which have been used in different shapes and sizes for many millennia. Application of tensile membranes started in mid-twentieth century and is set to continue in the future. Despite the fact that they are in use for more than half a century, they still amaze with their beauty and elegance. In addition to aesthetical qualities, they have advanced structural properties. Thinness, very low self-weight, and large spans are the result of their tensile nature. Their most common use is to provide protection from snow, rain, and direct sunlight, as open structures. Due to their extremely low thickness, they provide little thermal resistance. Therefore, in most climates, double membrane layers are used when tensile membrane structures are used for enclosing spaces. Application of tensile membranes is customary for large-scale sport arenas and covered public spaces. In such cases, tensile membranes provide protection for many people at the same time, thus increasing the risk in case of potential failures. This implies that the design and analysis of tensile membrane structures should be standardized. While in the USA, there is an American Standard, Tensile Membrane Structures, [1] and in Japan, there is MSAJ Standard [2], there is yet no European Standard on this topic. European Design Guide for Tensile Surface Structures [3] was published in 2004 and Prospect for European Guidance for the Structural Design of Tensile Membrane Structures [4] was published in 2016. Drafting of a Eurocode for Design of Tensioned Membrane Structures is under way at the moment. In order for it to be completed, comprehensive researches are conducted at institutions across Europe. The research presented in this paper is part of efforts to generate knowledge about all aspects concerning tensile membrane structures. 
The topics of this research are deflections resulting from the load actions on tensile membrane structures. These structures rely on tension prestress coupled with large changes of geometry to resist external loads. Their geometry changes under load are much larger compared to concrete, steel, or timber structures, even though the types and intensity of loads are the same. Snow load and wind load are regularly acting on tensile membrane structures and are routinely applied and analysed in specialized software. One of possible load types acting on tensile membrane structures is concentrated load. This load simulates workers standing on the roof while conducting maintenance, inspection, or repair. However, during the exploration of design and analysis of tensile membrane structures, it is noticed that this type of loading is often neglected in researches and even during structural analysis. For example, European Design Guide for Tensile Surface Structures and Prospect for European Guidance for the Structural Design of Tensile Membrane Structures do not mention this load type with regard to doubly curved tensile membrane structures. On the other hand, American Standard Tensile Membrane Structures direct designers to ASCE/SEI 7-10 [5] for design loads for buildings. ASCE/SEI 7-10 does take into account concentrated loads on roof structures. In addition, Huntington [6] directly states that "concentrated loads need to be taken into account during the structural analysis of tensile membranes." It is intended that the future Eurocode for Design of Tensioned Membrane Structures will be connected to other Eurocodes, including Eurocode 1 [7], which defines the loads acting on structures. Eurocode 1 also considers the point load actions on roof structures. Thus, it is obvious that in future, the point load actions will be an integral part of the structural analysis of tensile membrane structures, and yet, there is now very little knowledge on how tensile membranes respond to such loads.

There are only a few published researches related to deflections or point loads acting on membrane structures. Bridgens and Birchall [8] explored the significance of material properties in the design of tensile fabric structures and showed calculated maximal deflections under snow and wind load. Gosling et al. [9] compared the results from different analysis and design methodologies of membrane structures and reported on displacement values under snow and wind load. Wu and Ting [10] presented a research on large deflection analysis of 3D membrane structures by a 4-node quadrilateral intrinsic element. Zheng et al. [11] did a study on dynamic response of rectangular orthotropic membranes under impact loading. Weinberg and Neff [12] performed an investigation on large deformations and wrinkling on a geometrically exact thin membrane model. Selvadurai [13] researched deflections of a rubber membrane under rigid spherical indentor. Pearce et al. [14] analysed axisymmetric indentation of curved elastic membranes by a convex rigid indenter. Valdés et al. [15] presented a new methodology for the geometrically nonlinear analysis of orthotropic membrane structures and the example of its application on a membrane loaded with point load. Uhlemann et al. [16] showed in their work how deflections under point load are dependent on the value of the fictitious elastic constants of the material. Zhang et al. [17] studied the load-dependent mechanical behaviour of membrane materials and showed its effect to load-deflection curves. Researchers Katsikadelis and Tsiatas used analog equation method for large deflection analysis of membranes [18, 19]. Szyszkowski and Glockner studied spherical membranes subjected to concentrated loads [20-22]. Milošević [23] investigated dependence of membrane deflections on the position and intensity of point loads. Milošević et al. [24] researched effects of point load on changes of geometry and forces of a membrane structure.

This paper presents a research on the relation of point loads and tensile membrane structures and investigates the significance of point load actions compared to snow load actions with respect to deflections of the structure. This research builds on one of the published researches [24] which showed that point load can cause deflections comparable to those under snow load. The results motivated a new research presented herewith, aiming to discover whether point loads can produce larger membrane deflections than the usual snow load. Unlike point load actions, snow loads are regularly included in the structural analysis of tensile membrane structures. Therefore, there is much more information about the snow loads and hence they are considered to be a good comparison for the yet insufficiently explored point load actions. Exploring the membrane deflections under point load will help to mitigate the risk of damage to the structure or to the objects placed underneath. The objective of the research was to investigate a large number of models in order to check if point loads are more significant than snow loads under certain model parameters. The results of this research should help to better understand the importance of point load actions for tensile membrane structures and provide an easier transition for designers and engineers once the Eurocode for Design of Tensioned Membrane Structures comes in force.

\section{Methods}

The analysis started with the formulation of a model of a typical tensile membrane structure. The structure has a square base of $6 \times 6$ meters and the height of 1.5 meters. The membrane is prestressed with $3 \mathrm{kN} / \mathrm{m}$ in both warp and fill directions. The warp direction is set parallel to the edges of the base, as shown in Figure 1. Tensile modulus $\mathrm{E}$ of the membrane is $600 \mathrm{kN} / \mathrm{m}$ in both warp and fill, shear modulus $\mathrm{G}$ is $25 \mathrm{kN} / \mathrm{m}$, and Poisson coefficient is 0.3 . Thickness of the membrane is $1 \mathrm{~mm}$. It has flexible edges with $20 \mathrm{~mm}$ edge cables prestressed with $30 \mathrm{kN}$. This initial model was analysed in order to test the membrane behaviour under point load and snow load. Finite element software SOFiSTiK [25] was used to create the models and conduct the analysis. The membrane is divided into 144 finite elements. Analysis is conducted according to third-order theory.

As a typical point load, load with intensity of $1 \mathrm{kN}$ and a vertical downward direction were selected. According to Eurocode 1, this value is recommended for point load caused by workers on roofs. Snow load was modelled with $0.6 \mathrm{kN} / \mathrm{m}^{2}$ as in previous researches $[8,9,26]$, across the whole membrane, with a vertical downward direction. 

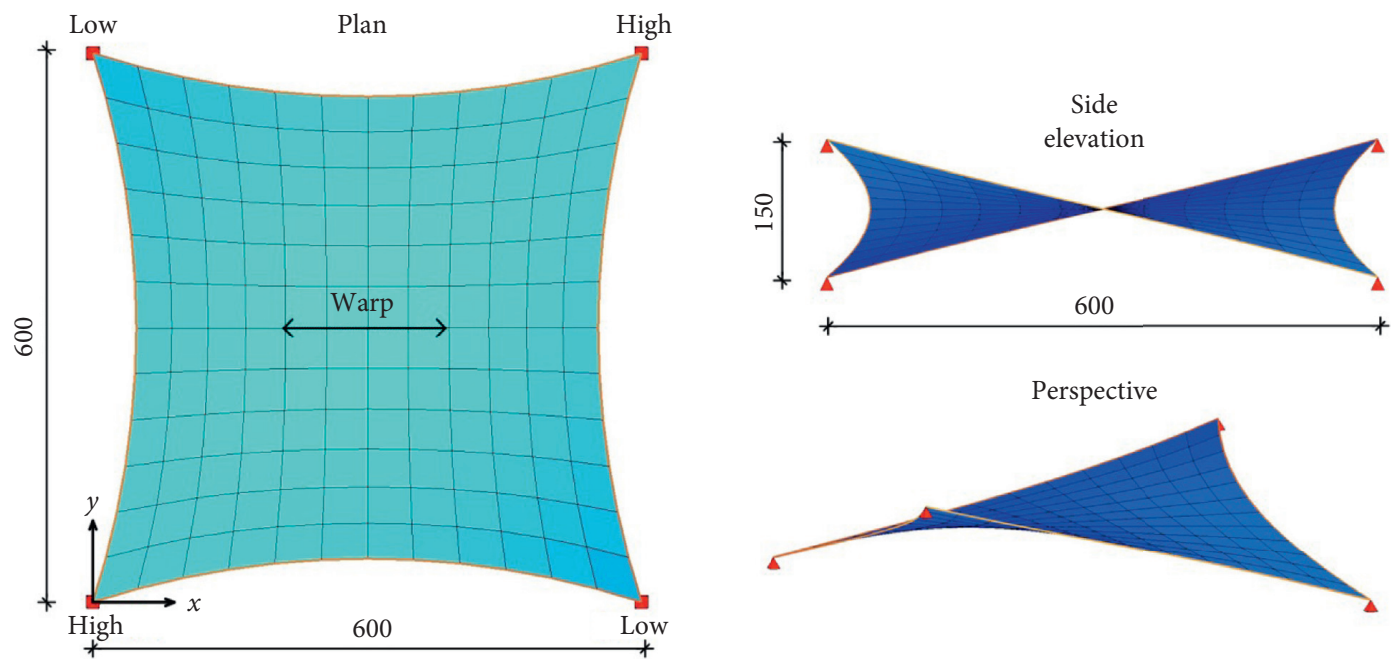

Figure 1: Geometry of the initial model.

In the first phase of the research, a point load was applied as a separate load case at every node of the initial model, except at the edge nodes. The snow load was also applied to the same model as a separate load case. The resulting deflections from these load cases were compared in such a manner that the maximal deflection from each load case with point load was compared to the deflections from snow load at the same point. This was done with the aim of evaluating the importance of point load actions to deflections of the initial model.

In the next phase of the research, the parameters of the initial model were varied in order to simulate many different tensile membrane structures. The goal was to check the conclusions obtained on the initial model by analysing other models of membrane structures. At the same time, this part of the research aimed to identify how different sets of model parameters will influence the relation between deflections caused by snow and point load and affect the importance of point load deflections. The list of six varied parameters is presented in Table 1 . The methodology set up with varying E modulus, $G$ modulus, patterning direction, and model height has already been used in [8] and later expanded by varying the position of the point load and the prestress intensity in [26]. However, unlike these two previous researches, this study focuses specifically on the comparison of point and snow load deflections in order to evaluate the significance of point load actions on tensile membrane structures.

Figure 2 shows all varied parameters of the model. There are 6 analysed heights of the model, and as shown in Figure 2 , they significantly affect the shape of the model. These heights are $0.5,1.0,1.5,2.0,2.5$, and $3.0 \mathrm{~m}$. Each of the models will be analysed for 7 positions of the point load, marked with letters A, B, C, D, E, F, and G, as shown in Figure 2. Due to the double symmetry of the model along diagonals, these points actually give results for 17 positions of the point load. Selected points are well distributed and provide a good insight into the behaviour of the entire membrane. There are 2 analysed patterning directions, the
TABLE 1: Variable parameters used in the research.

\begin{tabular}{lc}
\hline Parameters & Number of analysed values \\
\hline E modulus & 6 \\
G modulus & 4 \\
Patterning direction & 2 \\
Model height & 6 \\
Prestress intensity & 5 \\
Point load position & 7 \\
\hline
\end{tabular}

first one is where the warp is parallel to the edges of the base, and the second one is where the warp is along the diagonal connecting the two high supports. The model is double symmetric, the material is orthotropic, and the material properties are set to be the same in both principal directions. Thus, no change in results would occur if the material is rotated by $90^{\circ}$. Therefore, patterning directions are referred to as parallel and diagonal. In addition to these model parameters, the material properties are also varied. The selected values for tensile modulus $\mathrm{E}$ and shear modulus $\mathrm{G}$ of the membrane material are taken to be the same as in the previous research [8]. Despite the fact that not all combinations of material parameters are realistic, all of them are analysed. The prestress intensities of the membrane and the cables are also varied. The relation of their intensities is kept constant at $1: 10$, while the membrane prestress is set to be the same in warp and fill directions. Five different combinations of intensity values were used in the research.

By varying the values of first five parameters from Table 1 , a total of 1,440 different models were created. Since there are 1,440 different models, there will also be 1,440 snow load cases. Each model is loaded with point load at 7 different positions; therefore, there will be 10,080 point load cases. Values of snow load deflections are recorded at the same 7 positions as for the point load. One point load deflection and the corresponding snow load deflection at the same position of the same model are compared. These two values make one pair. There are a total of 10,080 pairs which will be compared. All varied parameters are identical for one 


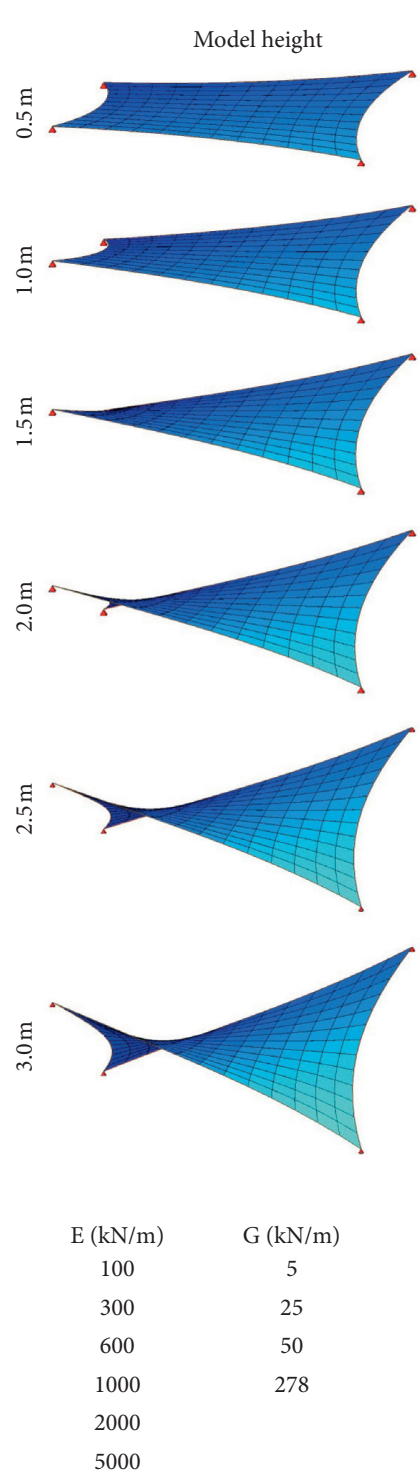

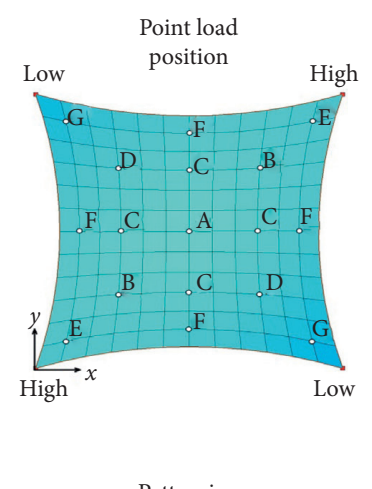
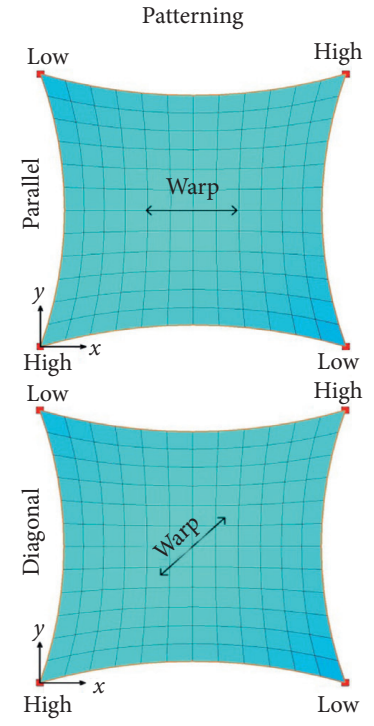

\begin{tabular}{ccc}
\multicolumn{3}{c}{ Prestress } \\
Comb. & Membrane & Cable \\
1 & $1 \mathrm{kN} / \mathrm{m}$ & $10 \mathrm{kN}$ \\
2 & $2 \mathrm{kN} / \mathrm{m}$ & $20 \mathrm{kN}$ \\
3 & $3 \mathrm{kN} / \mathrm{m}$ & $30 \mathrm{kN}$ \\
4 & $4 \mathrm{kN} / \mathrm{m}$ & $40 \mathrm{kN}$ \\
5 & $5 \mathrm{kN} / \mathrm{m}$ & $50 \mathrm{kN}$
\end{tabular}

FIgURE 2: Values of the variable parameters.

pair and only the load type is different. Therefore, each pair will be evaluated as larger deflections under point load, equal deflections under point and snow loads, or larger deflections under snow load.

\section{Results and Discussion}

3.1. Point Load Deflections of the Initial Model. The initial model was at first loaded with a single point load of $1 \mathrm{kN}$ at the centre of the membrane. This position is the position A used in the research. The central part of the membrane usually has the highest deflections when loaded with area loads. Deflections resulting from the point load acting on the centre of the initial model are presented in Figure 3.

Previous research showed that large deflections are highly concentrated around the position of the point load [23]. The initial model tested in this research shows the same behaviour. Maximal deflections of $138.3 \mathrm{~mm}$ are recorded

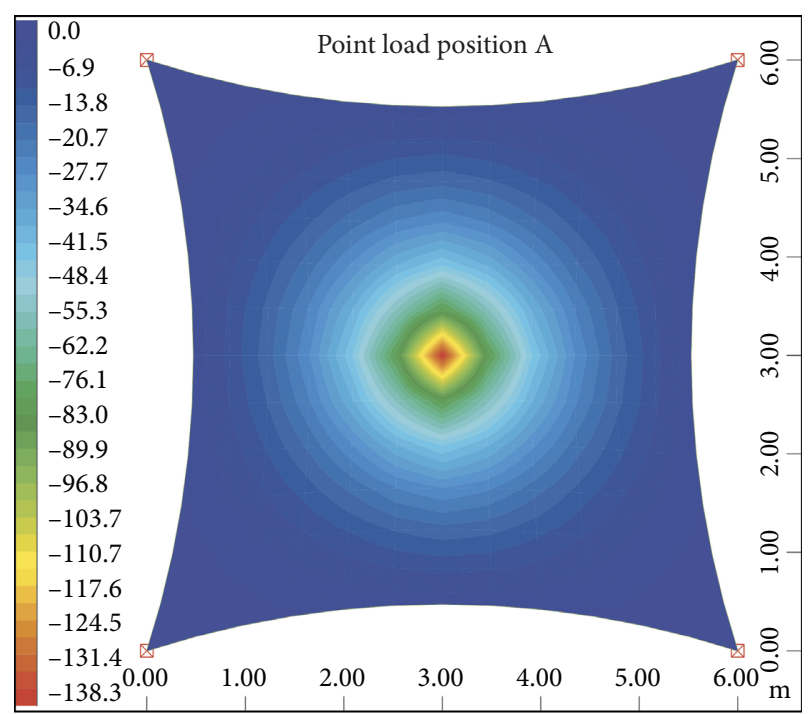

FIgURE 3: Membrane deflections of the initial model in global $Z$ direction for $1 \mathrm{kN}$ point load acting in position $\mathrm{A}(\mathrm{mm})$.

exactly in the position of the point load. Values shown in Figure 3 are negative because the $z$-axis is oriented upwards and deflections occur downwards. For the most parts, the membrane suffers very little deflections.

All 121 internal nodes of the membrane of the initial model were separately loaded with the $1 \mathrm{kN}$ point load in the same manner as the central node. It was expected that different positions of the point load would lead to similar behaviour of the membrane. Results for point load positions $\mathrm{B}$ to $\mathrm{G}$ are given in Figure 4.

The results presented in Figure 4 show the same pattern of behaviour for all positions of the point load. Large deflections are present locally around the position of the point load. Maximal deflection occurs at the position of point load. The greatest part of the membrane deflects very little. This is valid for all 121 analysed load cases. The most important difference between analysed load cases is the value of the maximal deflection. This value changes as the position of the point load changes. In order to show the maximal displacements under all load cases, Figure 5 is given. It presents the value of the maximal displacement of the membrane for different positions of the point load. Since the position of the point load and the position of the maximal displacement are always the same, the graphic in Figure 5 actually shows the membrane sensitivity to point load with respect to maximal deflections.

Figure 5 can also be regarded as a summary view of the possible maximal deflections for all positions of the point load. As expected, the results show that the membrane is the most sensitive at its centre. This is explained by its longest distance from the supports. The edge nodes were not analysed because the results would be highly dependent on the properties of the edge cables, so Figure 5 does not show any results for the peripheral finite elements. This graph will also serve for the comparison of deflections under point and snow load. 


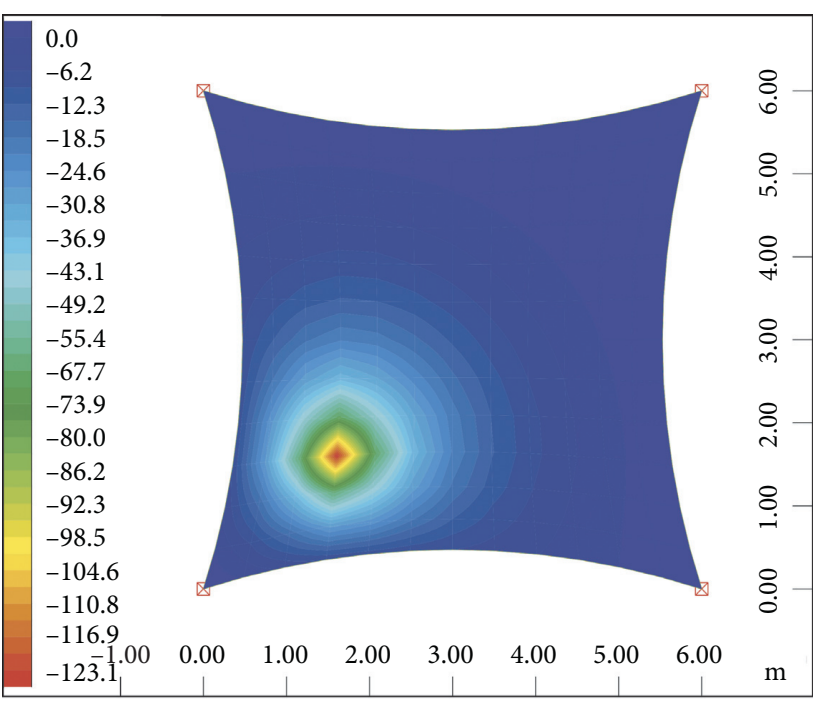

(a)

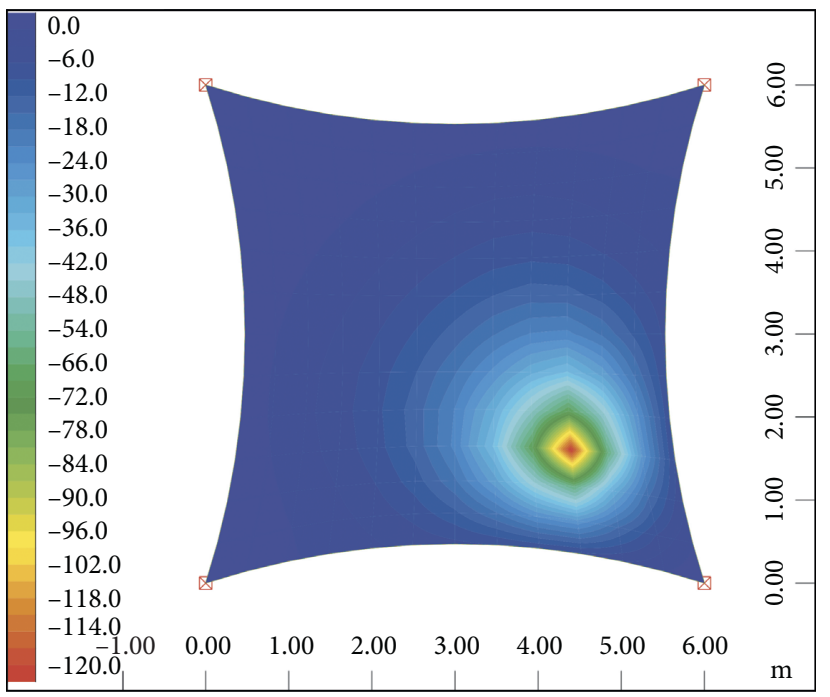

(c)

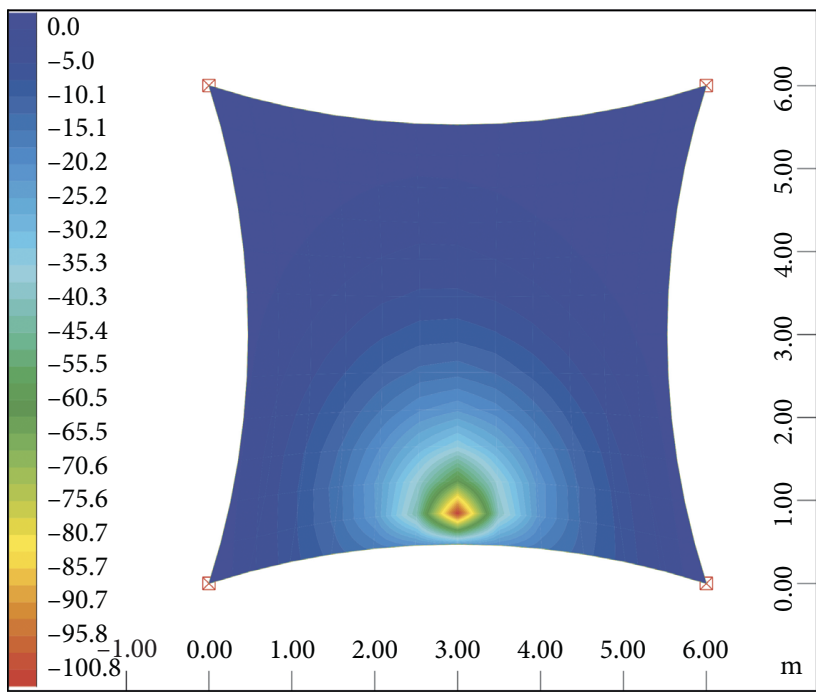

(e)

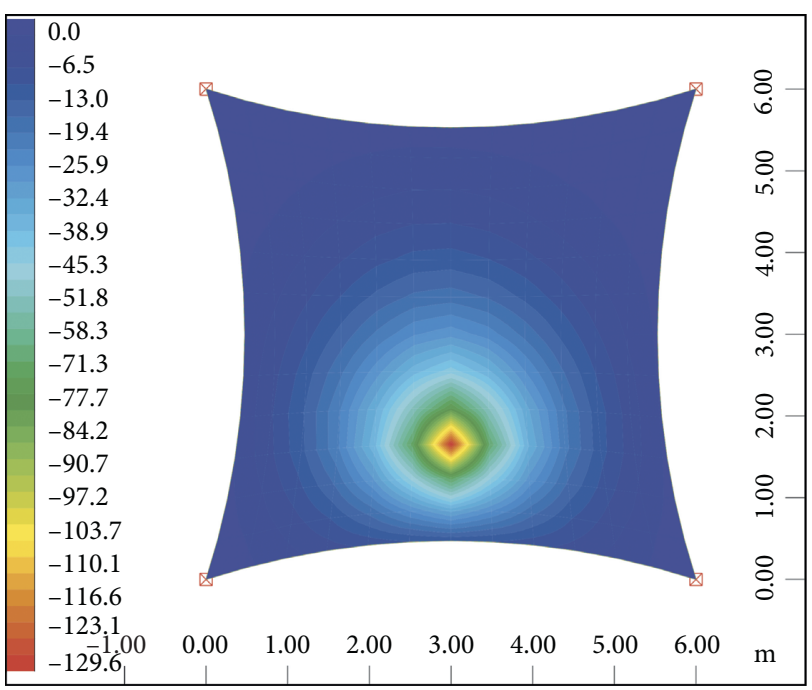

(b)

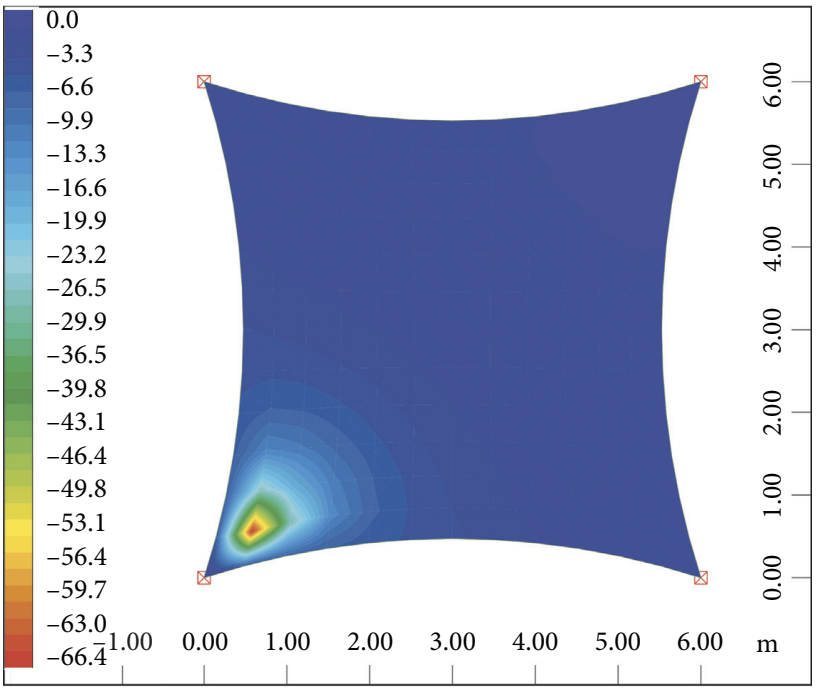

(d)

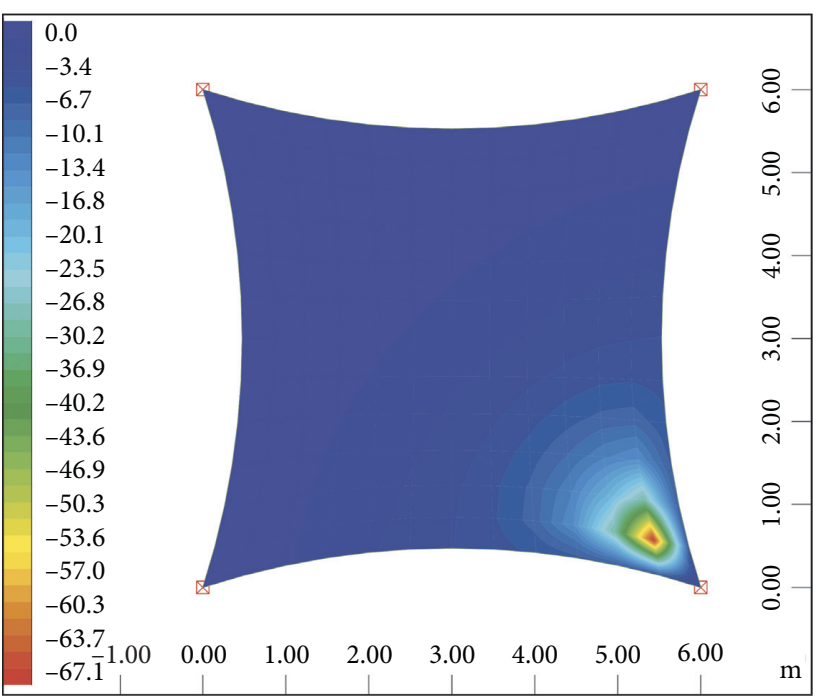

(f)

Figure 4: Membrane deflections of the initial model in global $Z$ direction for $1 \mathrm{kN}$ point load acting in positions B to $\mathrm{G}$ ( $\mathrm{mm}$ ). (a) Point load position B. (b) Point load position C. (c) Point load position D. (d) Point load position E. (e) Point load position F. (f) Point load position G. 


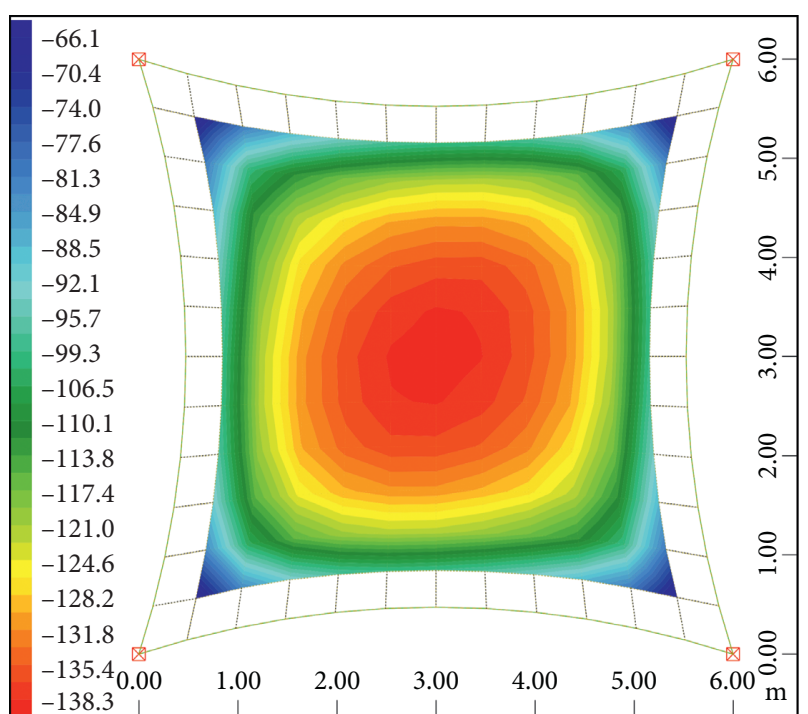

Figure 5: Possible maximal membrane deflections of the initial model in global $Z$ direction for different positions of the $1 \mathrm{kN}$ point load $(\mathrm{mm})$.

3.2. Snow Load Deflection of the Initial Model. Snow load is applied to the initial model independently from the point load. It is modelled with the value of $0.6 \mathrm{kN} / \mathrm{m}^{2}$ across the entire surface of the membrane. Total weight of the snow load is about $18 \mathrm{kN}$, while weight of the point load is only $1 \mathrm{kN}$. Therefore, it is expected that the snow load will produce larger deflections compared to the point load, despite the fact that point load is concentrated while the snow load is evenly distributed. Deflections of the membrane in global $Z$ direction are given in Figure 6 .

The results presented in Figure 6 show that the maximal deflections are recorded at the centre of the membrane and that they decrease towards the supports. The value of the maximal deflection is $245.9 \mathrm{~mm}$, which is larger than deflections caused by the point load, as expected. There are no parts of the membrane that undergo uplift.

3.3. Comparison of Deflections of the Initial Model. It is obvious that maximal deflections from $0.6 \mathrm{kN} / \mathrm{m}^{2}$ snow load are higher compared to the largest maximal deflections caused by $1 \mathrm{kN}$ point load. As the next step, it was decided that not only the point load position with the maximal deflection, but all other positions of the point load should be compared to the snow load as well. Thus, deflections from snow load are compared to maximal deflections from all positions of the point load. Results are presented in Figure 7.

Results presented in Figure 7 practically show the results shown in Figure 6 subtracted from results shown in Figure 5. The centre of the membrane has a value of $107.5 \mathrm{~mm}$ which means that $0.6 \mathrm{kN} / \mathrm{m}^{2}$ snow load produces larger deflections compared to $1 \mathrm{kN}$ point load acting at this point. However, contrary to expectations, there are points on the membrane which have negative values. This means that there are points on the membrane at which point loads produce larger deflections than snow loads. In the central

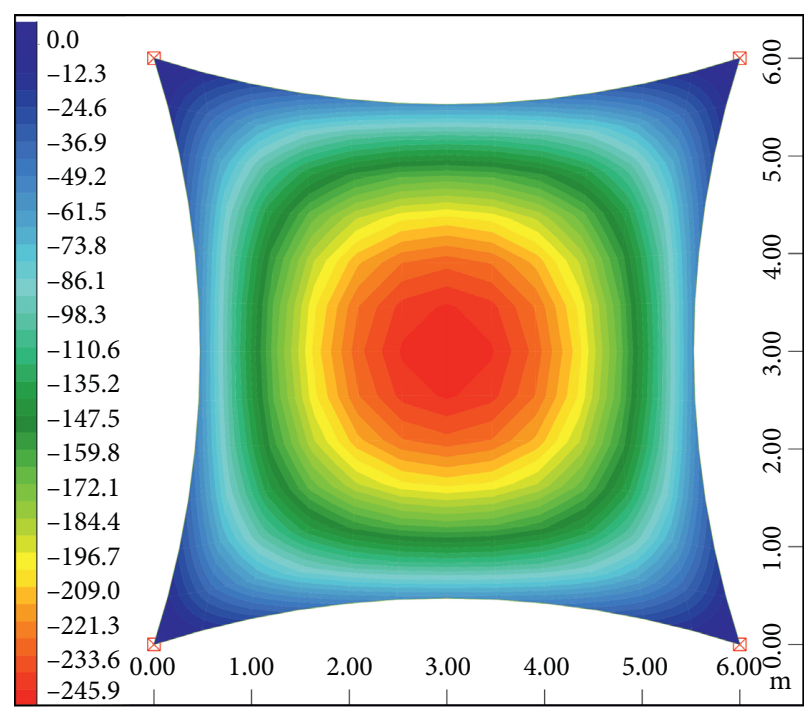

Figure 6: Membrane deflections of the initial model in global $Z$ direction for $0.6 \mathrm{kN} / \mathrm{m}^{2}$ snow load $(\mathrm{mm})$.

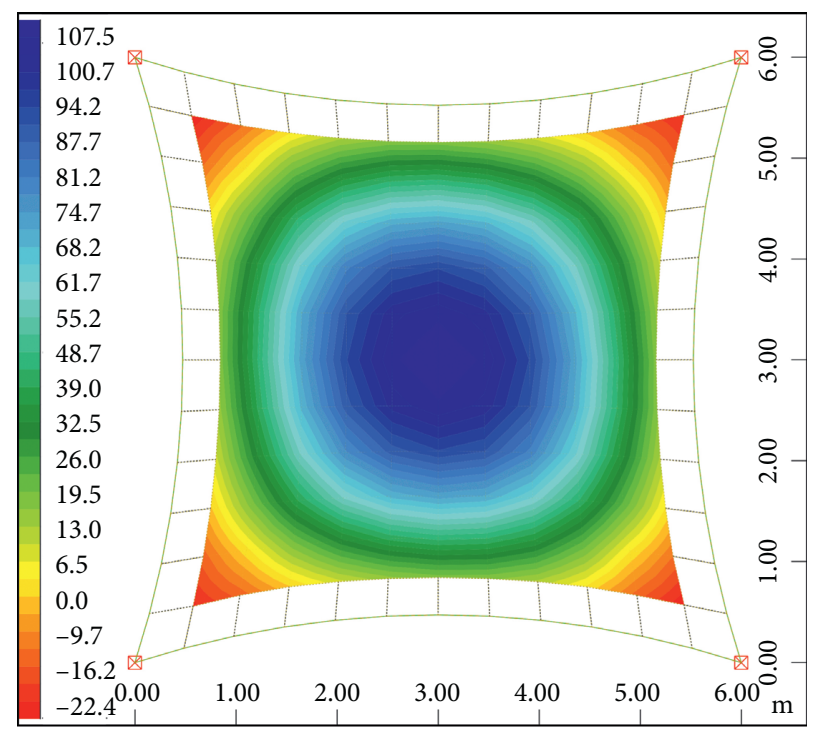

Figure 7: Difference in deflections caused by $1 \mathrm{kN}$ point load at different positions and $0.6 \mathrm{kN} / \mathrm{m}^{2}$ snow load in global $Z$ direction $(\mathrm{mm})$.

area of the membrane, snow load produces larger deflections. The areas where the values are negative are smaller than the area where values are positive. This means that a larger part of the membrane of the initial model is more sensitive to snow load than to point loads. Deflections from the snow load get lower towards supports; likewise, deflections get lower as the position of the point load approaches supports. However, deflections from snow load decrease more rapidly, thus becoming smaller than deflections from the point load near the supports. For example, the internal node closest to low supports shows a value of $-22.4 \mathrm{~mm}$. Therefore, point load acting at this node will produce $22.4 \mathrm{~mm}$ larger deflections compared to deflections from snow load at the same point. 
The obtained results are very significant, since point load actions on membrane structures have been mostly neglected in European literature and researches. In cases where engineers wanted to include the point loads in the structural analysis, they had to do so based on their own experience and engineering logic, there being no guidelines on how to apply point loads on membranes. The most logical option would be to apply the point load in the centre of the membrane in case of simple membrane shapes, while for more complex membrane forms, several positions would have to be checked. It was not expected to have significant point load deflections in areas close to supports, since the values of point load deflections are the lowest in these areas. However, the results of the presented research show that point loads can produce deflections larger than those from snow load in the areas close to the supports. This finding is very important as it shows that unaccounted point load can cause damages during the life-time of a structure by deflecting the membrane so it gets in contact with objects placed underneath. Such cases can be prevented by incorporating point loads with appropriate positions in the structural analysis. The next phase of the research was dedicated to demonstrating that this finding is not an exception occurring only on the initial model, but rather a previously unknown behaviour of tensile membranes existing in different models.

3.4. Comparison of Deflections in All Models. In the next step of the research, all models have been separately loaded with point load at 7 chosen positions and with snow load. After the analysis has been conducted on all models, the resulting deflections from point load and from matching snow load at the same point of the same model were paired and compared. The results surprisingly showed that among the 1,440 models, there is not even one model in which the deflections from snow load are higher in all 7 analysed points. On the other hand, there are 491 models in which point load produces higher deflections in all 7 points. This means there are $34 \%$ of models where point loads produce larger deflections at 17 points on the membrane, including both analysed and symmetric points. It is reasonable to expect that, in most of these models, point load would produce larger deflections in any point of the model. The number of models according to the positions with higher point load deflections is given in Table 2. Among the 10,080 analysed pairs, there are 6,079 in which the membrane deflections are larger under point load. The fact that point load deflections were dominant in over $60 \%$ of the analysed pairs was not initially anticipated.

One of the models where all 7 analysed points are more sensitive to point load is further analysed and given in Figure 8. Further analysis was conducted in order to compare deflections of all internal points of the model, in the same way as on the initial model. This model has the following properties: height is $1.5 \mathrm{~m}$, prestress combination $3, \mathrm{E}=600 \mathrm{kN} / \mathrm{m}$, $\mathrm{G}=25 \mathrm{kN} / \mathrm{m}$, and diagonal patterning. The only difference from the initial model is in the direction of the patterning. In Figure 8 , the deflections for different point load positions and
TABle 2: Number of models with larger deflections under point load.

\begin{tabular}{lc}
\hline $\begin{array}{l}\text { Number of positions with larger deflections } \\
\text { under point load }\end{array}$ & $\begin{array}{c}\text { Number of } \\
\text { models }\end{array}$ \\
\hline 0 & 0 \\
1 & 2 \\
2 & 587 \\
3 & 147 \\
4 & 97 \\
5 & 59 \\
6 & 57 \\
7 & 491 \\
& Total 1,440 \\
\hline
\end{tabular}

from snow load, as well as their comparison, are given. The results show that the behaviour of the model in question is not the same as that of the initial model. In this case, point load produces larger deflections not only in areas close to supports but at all internal points of the membrane, including all analysed and their symmetric points. At the centre of the membrane, deflections are $2.1 \mathrm{~mm}$ larger under point load and the biggest difference of $33.3 \mathrm{~mm}$ is at the node closest to low supports. Therefore, results prove that point load positions close to supports are the most significant but also show that, in some cases, even their position in the centre can produce larger effects than the analysed snow load.

This example of a typical membrane structure shows that there are models which are more sensitive to point loads across the whole membrane. This once again speaks in favour of the importance of taking point loads into account during the structural analysis of tensile membrane structures. However, it should be stated that patterning direction, as the only difference from the initial model, is not a decisive factor for the sensitivity to point loads in all other cases, as will be shown in the analysis of parameters influencing the importance of point load.

The last phase of this research was dedicated to investigating how different parameters of the model affect the relation of deflections under point and snow loads. Therefore, the results are sorted and presented in Figure 9 for the varied parameters. This figure shows the number of pairs with larger deflections under point load or under snow load. The results are presented separately for larger deflections under point load for diagonal and parallel patterning and in total. Different patterning directions are presented separately in order to show that this is not the only factor for determining deflection sensitivity to loads.

In order to check how the height of the model affects the significance of point loads for membrane deflections, results were systematized according to different models' heights. These results are presented in Figure 9(a). The obtained results show that deflection sensitivity to point load increases with the curvature of the membrane and that models with greater height are more likely to have larger deflections under point load than under snow load. At the lowest analysed height, the number of pairs in models with diagonal and with parallel patterning is similar, but for all other heights, there are more pairs with diagonal patterning which have larger deflections under point loads. 


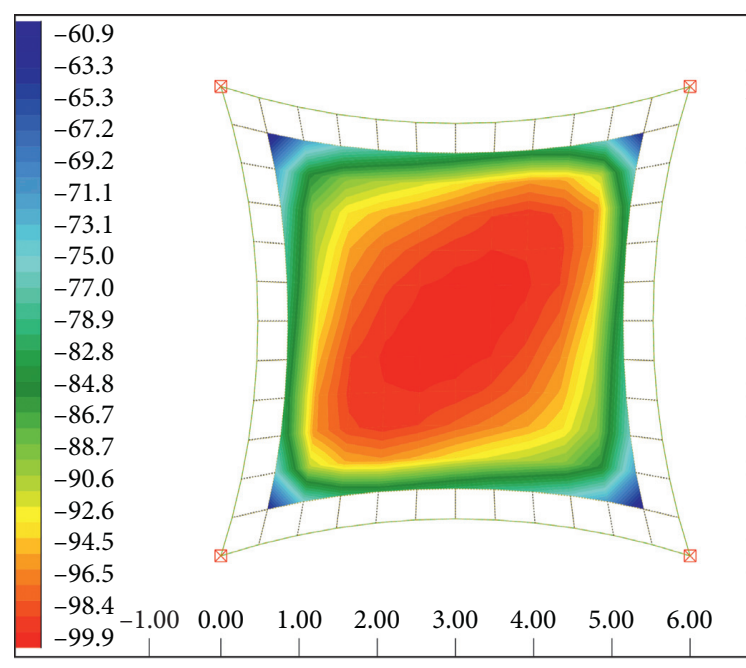

(a)

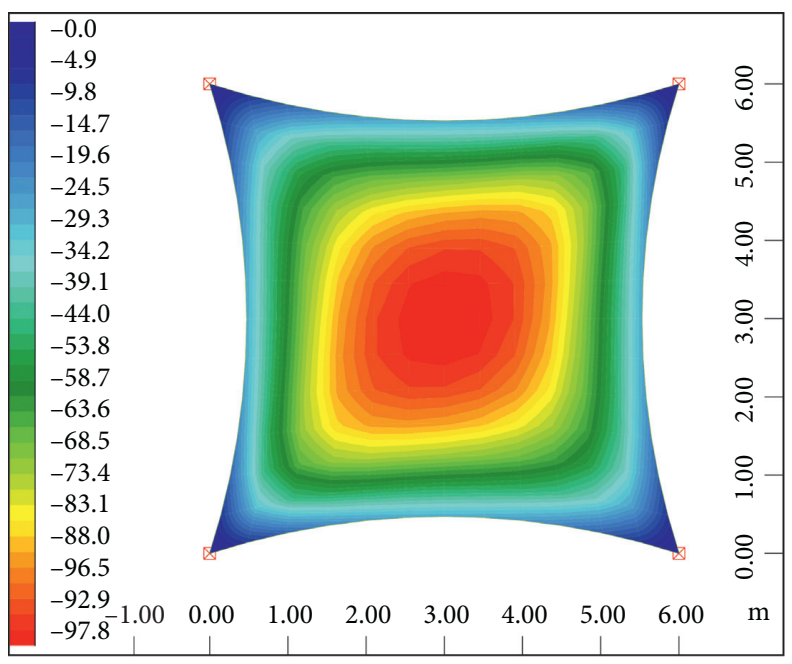

(b)

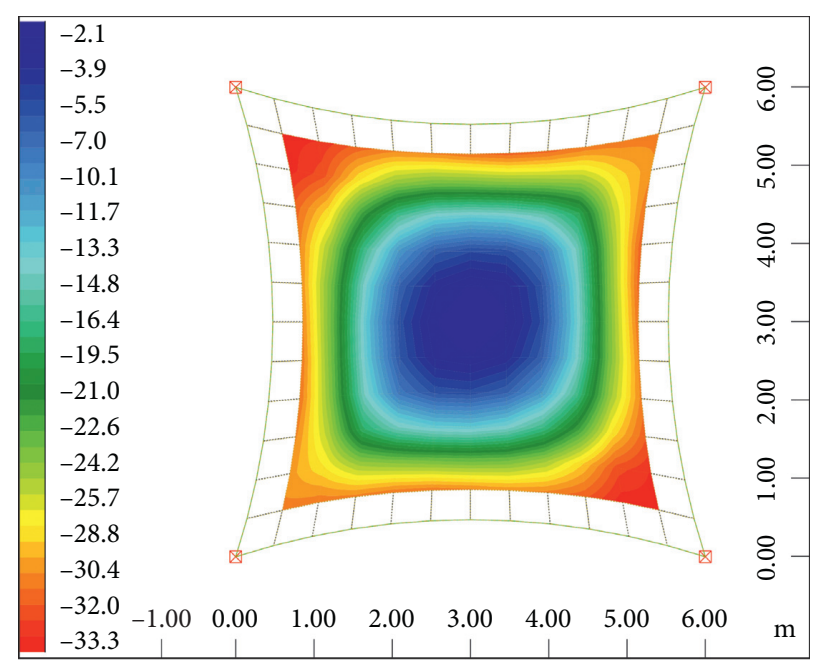

(c)

FIgURe 8: Comparison of deflections for one of the models ( $\mathrm{mm}$ ). (a) Sensitivity to $1 \mathrm{kN}$ point load. (b) Deflections for $0.6 \mathrm{kN} / \mathrm{m}^{2} \mathrm{snow}$ load. (c) Their difference.

The results sorted according to different prestress combinations are given in Figure 9(b). Based on the presented results, it can be concluded that membranes with lower prestress values are more prone to larger deflections under point load. As the prestress of the membrane and cables increases, the number of pairs with larger point load deflections decreases. For all prestress combinations, there are more pairs with larger point load deflections among models with diagonal patterning compared to parallel patterning. Under all prestress combinations, there are more pairs with larger point load than snow load deflections.

The results sorted according to E modulus values of the membrane, given in Figure 9(c), show significant differences between models with diagonal and parallel patterning. Models with parallel patterning are affected very little by the change of the $\mathrm{E}$ modulus value. There is a relatively constant number of pairs with parallel patterning in which the point load causes larger deflections at all analysed values of the $\mathrm{E}$ modulus. The number of pairs with larger deflections under point load among models with diagonal patterning increases with the increase of $\mathrm{E}$ modulus. For the lowest $\mathrm{E}$ modulus value, there are fewer pairs with diagonal patterning than with parallel patterning, in which the point load has larger deflections. The total number of pairs with larger deflections under point load increases with the increase of $\mathrm{E}$ modulus, except for the value of $5000 \mathrm{kN} / \mathrm{m}$ when it decreases slightly. Only among models with $\mathrm{E}=100 \mathrm{kN} / \mathrm{m}$, there are more pairs with larger deflections under snow load.

The results arranged by $\mathrm{G}$ modulus values, presented in Figure 9(d), show different behaviour from the results obtained by varying $\mathrm{E}$ modulus. The number of pairs with larger deflections under point load in models with diagonal patterning is almost constant for all $\mathrm{G}$ modulus values. The number of pairs with larger point load deflections in models with parallel patterning increases with the increase of the $G$ modulus value. The total number of pairs more sensitive to point load also increases with the increase of $\mathrm{G}$ modulus. This practically means that the $G$ modulus value impacts 


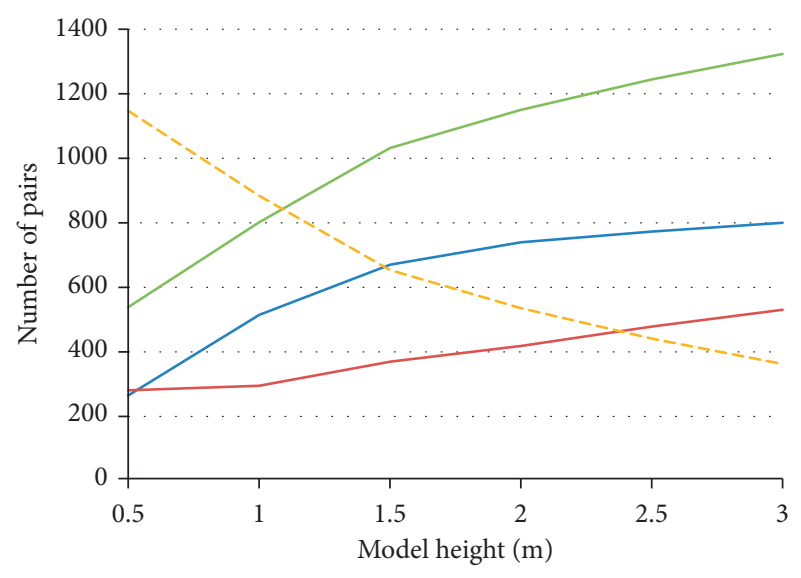

Point load-diagonal patterning
$\_$Point load-parallel patterning
- Point load-total
- Snow load

(a)

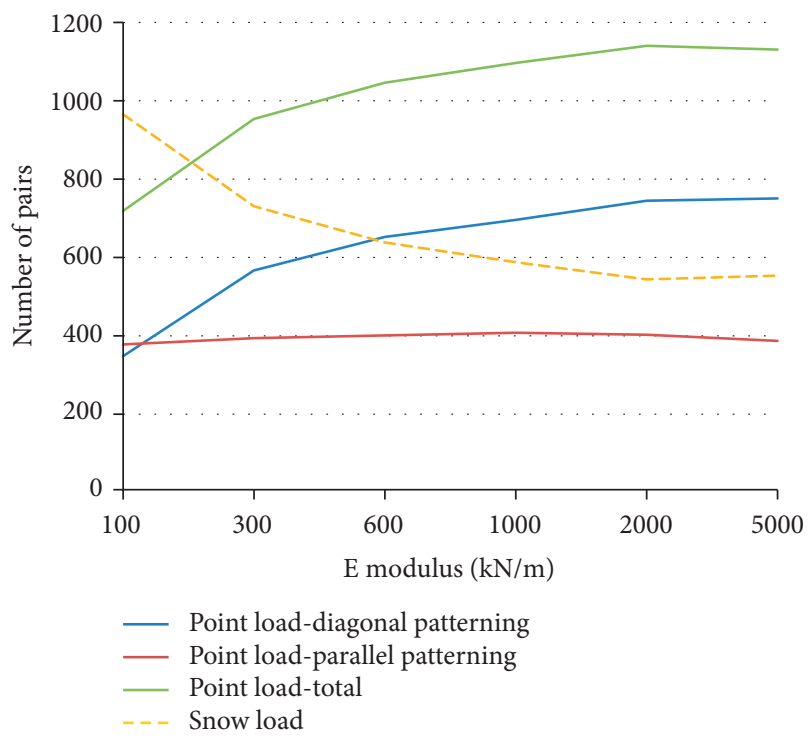

(c)

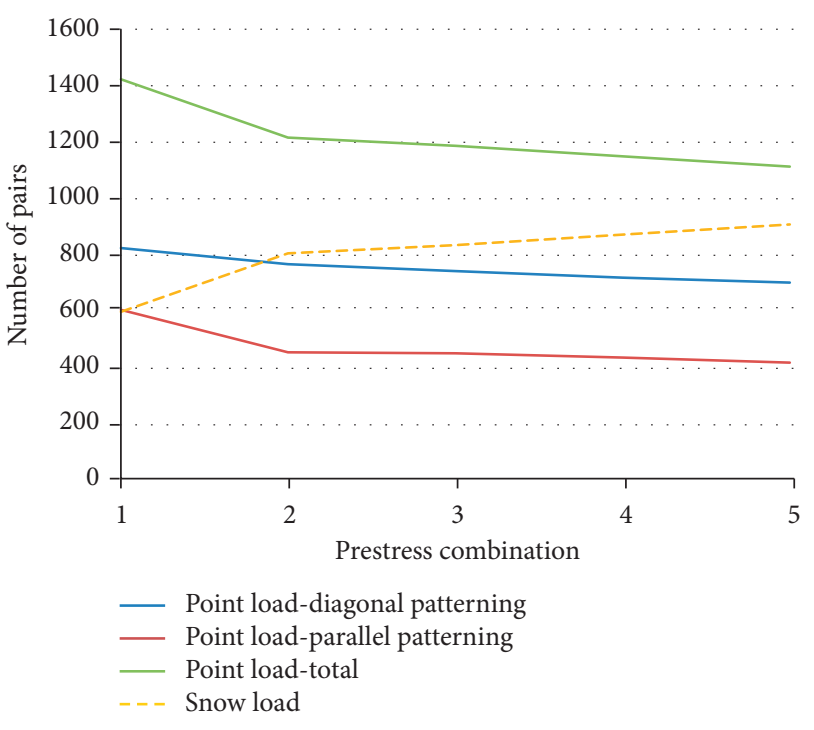

(b)

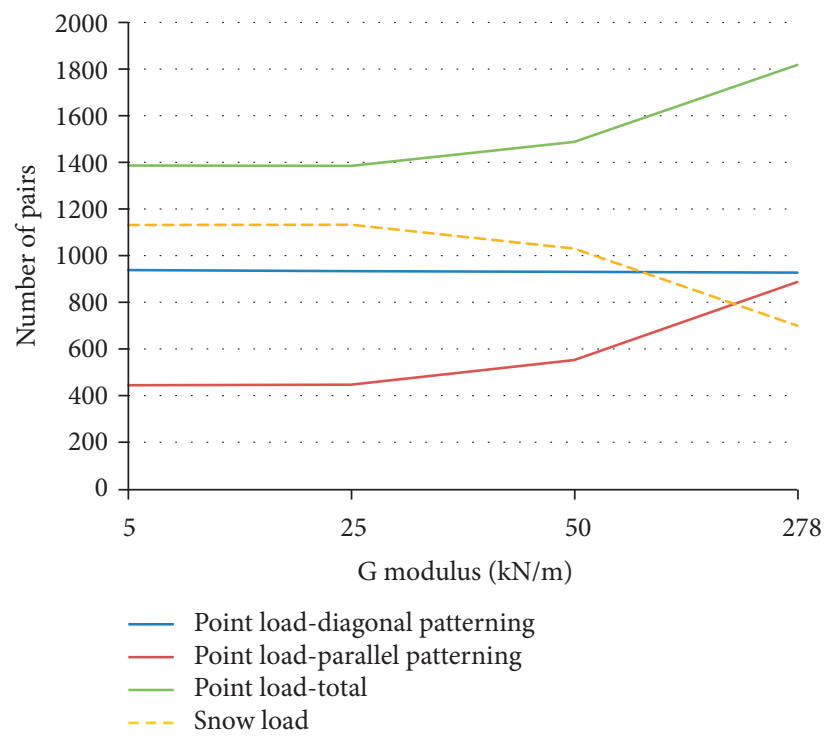

(d)

Figure 9: Number of pairs with larger deflections under point or snow load depending on the following parameters. (a) Model height. (b) Prestress combination. (c) E modulus. (d) G modulus.

significantly more the models with parallel patterning and that these models are more sensitive to point load as the $G$ modulus value increases. Under all values of $G$ modulus, there are more pairs with larger deflections under point load than under snow load.

Finally, the results obtained in this research are sorted according to the seven analysed positions on the models. They are presented in Figure 10. This figure shows the number of models which have larger deflections under snow load, represented in yellow columns, and the number of models with larger deflections under point load. The number of models where the point load produces larger deflections is once again divided to those with diagonal patterning, shown by blue columns, and those with parallel patterning, shown by red columns. The snow load causes larger deflections of a larger number of models at points A, B, C, and D. Points E and G are particularly interesting for proving the importance of point load actions. There are 1438 out of 1440 models in which the point load produces larger deflections in point $\mathrm{E}$, which is close to the high support. In all analysed models, point load produces larger deflections than the analysed snow load in point $G$, which is the closest to the low support. This leads to the conclusion that deflections under point load should always be checked close to supports in all models similar to the analysed models. Even at the centre of the membrane, which is critical for the snow load, there are 493 models, or 34\% of models, in which the point load will produce larger deflections. The results of this research show that point load effects on deflections are in many cases larger than the effects of the standard snow load acting on the tensile membrane structure. 


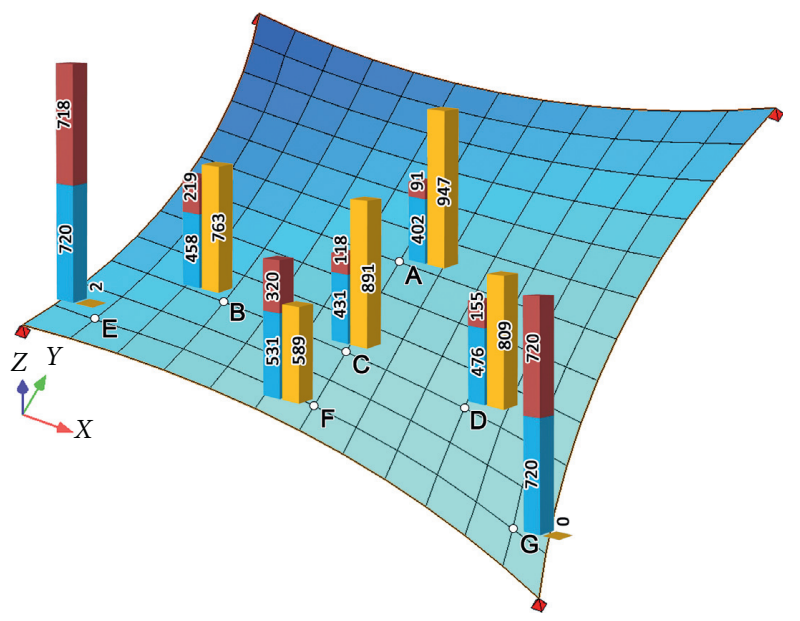

- Point load: parallel patterning

- Point load: diagonal patterning

- Snow load

Figure 10: Number of models sorted according to higher deflections at analysed points.

\section{Conclusions}

In this research, deflections from point load were compared to deflections from snow load, acting on models of tensile membrane structures. Six parameters were varied in order to create 1,440 different models. A total of 10,080 pairs of deflection values were extracted and analysed from these models. Based on this large data sample, conclusions about the importance of point load actions on deflections of tensile membrane structures and eventually their design and analysis were drawn.

The results obtained in this research show that all analysed models have larger deflections under point load than under snow load in at least one point. This point is the internal membrane node closest to the low support of the structure. In addition, almost all models show the same behaviour for the internal node closest to the high support. At other analysed positions, these two loads produce larger deflections on a comparable number of models. Even at the centre of the membrane, where snow load deflections are most frequently checked, there are $34 \%$ of models with higher deflections under point load. These findings undoubtedly prove the significance of including point load actions in design and analysis of tensile membrane structures.

The sets of data obtained during the research were further used to explore how changes of parameters affect the likeliness of the model having larger deflections under point load than under snow load. It is concluded that models with diagonal patterning have more chances of having larger deflections under point load. Larger curvature of the models also increases the likeliness of the model having larger deflections under point load. Models with higher prestress intensity of the membrane and the edge cables are less likely to have larger point load deflections. Finally, models with diagonal patterning and higher E modulus and models with parallel patterning and larger $G$ modulus have higher chances of having larger deflections under point load.

The fact that the analysis and design of tensile membrane structures are still not standardized in Europe creates room for uncertainties, mistakes, and application of different routines. One of the areas with most unknown aspects is the analysis of point load actions. It is not clear when to apply them, with what intensity, at what positions, what to expect with regard to the result of their actions, and finally how to try and minimize their effects in case this is necessary. The results of this research contribute towards better understanding of point load actions on tensile membranes and help to facilitate their standardization in Europe. The conclusions of the research will assist in increasing the safety of tensile membrane structures and lead to the advancement in the design and analysis of tensile membrane structures.

\section{Data Availability}

The Microsoft Excel Worksheet data used to support the findings of this study are available from the corresponding author (vukamer@yahoo.com) upon request.

\section{Disclosure}

The results presented in this paper are also discussed in the first author's doctoral thesis.

\section{Conflicts of Interest}

The authors declare that they have no conflicts of interest.

\section{Acknowledgments}

The authors would like to thank SOFiSTiK AG and Focus Computers d.o.o. for providing a license to use the software SOFiSTiK for research purposes.

\section{References}

[1] American Society of Civil Engineers, Tensile Membrane Structures, ASCE Standard, Reston, VA, USA, 2010.

[2] Membrane Structures Association of Japan, Testing Method for Elastic Constants of Membrane Materials, Membrane Structures Association of Japan, Tokyo, Japan, 1995.

[3] B. Forster and M. Mollaert, European Design Guide for Tensile Surface Structures, TensiNet, Brussels, Belgium, 2004.

[4] N. Stranghöner, J. Uhlemann, F. Bilginoglu et al., Prospect for European Guidance for the Structural Design of Tensile Membrane Structures, Joint Research Centre, Ispra, Italy, 2016.

[5] American Society of Civil Engineers, Minimum Design Loads for Buildings and Other Structures, ASCE Standard, Reston, VA, USA, 2010.

[6] C. G. Huntington, Tensile Fabric Structures: Design, Analysis and Construction, ASCE, Reston, VA, USA, 2013.

[7] European Committee for Standardization, EN1991 2002Eurocode 1: Actions on Structures, European Committee for Standardization, Brussels, Belgium, 2002.

[8] B. Bridgens and M. Birchall, "Form and function: the significance of material properties in the design of tensile fabric structures," Engineering Structures, vol. 44, pp. 1-12, 2012. 
[9] P. D. Gosling, B. N. Bridgens, A. Albrecht et al., "Analysis and design of membrane structures: results of a round robin exercise," Engineering Structures, vol. 48, pp. 313-328, 2013.

[10] T.-Y. Wu and E. C. Ting, "Large deflection analysis of 3D membrane structures by a 4-node quadrilateral intrinsic element," Thin-Walled Structures, vol. 46, no. 3, pp. 261-275, 2008.

[11] Z.-L. Zheng, W.-J. Song, C.-J. Liu, X.-T. He, J.-Y. Sun, and Y.-P. Xu, "Study on dynamic response of rectangular orthotropic membranes under impact loading," Journal of Adhesion Science and Technology, vol. 26, no. 10-11, pp. 1467-1479, 2012.

[12] K. Weinberg and P. Neff, "A geometrically exact thin membrane model-investigation of large deformations and wrinkling," International Journal for Numerical Methods in Engineering, vol. 74, no. 6, pp. 871-893, 2008.

[13] A. P. S. Selvadurai, "Deflections of a rubber membrane," Journal of the Mechanics and Physics of Solids, vol. 54, no. 6, pp. 1093-1119, 2006.

[14] S. P. Pearce, J. R. King, and M. J. Holdsworth, "Axisymmetric indentation of curved elastic membranes by a convex rigid indenter," International Journal of Non-linear Mechanics, vol. 46, no. 9, pp. 1128-1138, 2011.

[15] J. G. Valdés, J. Miquel, and E. Oñate, "Nonlinear finite element analysis of orthotropic and prestressed membrane structures," Finite Elements in Analysis and Design, vol. 45, no. 6-7, pp. 395-405, 2009.

[16] J. Uhlemann, N. Stranghöner, and K. Saxe, “Tensile structures: investigation into the determination of elastic constants of fabrics," Journal of the International Association for Shell and Spatial Structures, vol. 56, no. 1, pp. 25-35, 2015.

[17] Y. Zhang, Q. Zhang, Z. Yang, L. Chen, and Y. Cao, "Loaddependent mechanical behavior of membrane materials and its effect on the static behaviors of membrane structures," Journal of Materials in Civil Engineering, vol. 27, pp. 1-11, 2015.

[18] J. T. Katsikadelis and G. C. Tsiatas, "The analog equation method for large deflection analysis of heterogeneous orthotropic membranes: a boundary-only solution," Engineering Analysis with Boundary Elements, vol. 25, no. 8, pp. 655-667, 2001.

[19] G. C. Tsiatas and J. T. Katsikadelis, "Large deflection analysis of elastic space membranes," International Journal for Numerical Methods in Engineering, vol. 65, no. 2, pp. 264-294, 2006.

[20] W. Szyszkowski and P. G. Glockner, "Spherical membranes subjected to concentrated loads," Engineering Structures, vol. 9, no. 1, pp. 45-52, 1987.

[21] W. Szyszkowski and P. G. Glockner, "Spherical membranes subjected to vertical concentrated loads: an experimental study," Engineering Structures, vol. 9, no. 3, pp. 183-192, 1987.

[22] W. Szyszkowski and P. G. Glockner, "Finite deformation and stability behaviour of spherical inflatables under axi-symmetric concentrated loads," International Journal of Nonlinear Mechanics, vol. 19, no. 5, pp. 489-496, 1984.

[23] V. Milošević, "Dependence of membrane deflection on the position and intensity of point loads," Structural Engineering International, vol. 25, no. 1, pp. 20-25, 2015.

[24] V. Milošević, B. Marković, and D. Stojić, "Effects of point loads on membrane structures," Građevinar, vol. 70, no. 12, pp. 1033-1041, 2018.

[25] SOFiSTiK AG, ASE General Static Analysis of Finite Element Structures, SOFiSTiK AG, Oberschleissheim, Germany, 2015.

[26] V. Milošević, The aspect of change of geometry under point load in designing prefabricated membrane structures, Ph.D. thesis, University of Niš, Niš, Serbia, 2018. 